\title{
BLACK POWER: UM PROJETO EMANCIPATÓRIO E ANTIRRACISTA NA FACELI
}

\section{BLACK POWER: AN EMANCIPATORY AND ANTI-RACISM PROJECT IN FACELI}

\author{
Joana Lúcia Alexandre de Freitas \\ Faculdade de Ensino Superior de Linhares (Faceli) \\ Yuri Miguel Macedo \\ Universidade Federal do Sul da Bahia (UFSB) \\ Universidade Federal do Espirito Santo (UFES)
}

\section{RESUMO}

Dialogismos sobre racismo no Brasil são taxados de vitimismo. A população Brasileira foi ensinada a ignorar a existência do racismo e a exercê-lo de forma velada. Para reconhecer basta perceber que a maioria da população é preta e parda, e não ocupam cargos de poder, ao contrário, compõem a parcela de pobres, presidiários, ou seja, estão à margem da sociedade. Diante dessa situação, justifica-se promover ações que promovam reflexões e AÇÕES para esclarecer falsas ideologias, e, despertar mais pessoas a combater esse mal estar instalado na população brasileira. Para tanto, este artigo traz um relato de experiência sobre um projeto denominado Black Power que se propôs a realizar ações antirracistas na cidade de Linhares-ES. Os resultados são muito promissores conseguiu-se envolver acadêmicos, pessoas da comunidade civil, e demais brasileiros através das redes sociais.

Palavras-chave: Black Power, Racismo, Antirracismo, Faceli, Educação.

\begin{abstract}
Dialogisms about racism in Brazil are classified as victimism. The Brazilian population was taught to ignore the existence of racism and to exercise it in a veiled manner. To acknowledge it is enough to realize that the majority of the population is black and brown, and does not occupy positions of power, on the contrary, they make up the portion of the poor, prisoners, that is, they are on the margins of society. In view of this situation, it is justified to promote actions that promote reflections and ACTIONS to clarify false ideologies, and to awaken more people to combat this malaise installed in the Brazilian population. To this end, this article brings an experience report on a project called Black Power that proposed to carry out anti-racist actions in the city of Linhares-ES. The results are very promising, it was possible to involve academics, people from the civil community, and other Brazilians through social networks.
\end{abstract}

Keywords: Black Power, Racism, Anti-Racism, Faceli, Education. 


\title{
Abram-se as cortinas
}

\begin{abstract}
É tempo de formar novos quilombos, em qualquer lugar que estejamos, e que venham os dias futuros, salve 2020, a mística quilombola persiste afirmando: "a liberdade é uma luta constante". Conceição Evaristo (2019, acesso em 2020).
\end{abstract}

Ao encetar esse escrito com esse pensamento de Conceição Evaristo, é notório que o (des)governo no ano de 2019 e 2020, foi e é um processo constante de cerceamento de direitos e principalmente, com o aumento expressivos de ataques as instituições públicas e políticas públicas que garantem acesso à população preta, pobre e periférica, chancelado por um fascismo e pelo cristianismo.

A conjuntura da globalização que caracteriza o mundo atual, evidencia um momento bastante embaraçoso na história da humanidade: a produção do binômio: riqueza e pobreza como pontos distintos que parecem conduzir o homem a extremos diferentes como se fossem uma ruptura. Se por um lado pareça assustador, por outro não se pode negar os progressos alcançados, consequentes da lógica capitalista. Os direitos fundamentais e sociais correm riscos cada dia mais com esse processo de uma sociedade brasileira neoliberal, cabe aqui ressaltar que vamos pautar nossas análises justamente na pasta da Educação, que de acordo com Macedo (2018), a educação tem por papel fissurar todas as estruturas sociais para a transformação social, ou seja, tornar os estudantes críticos, deixa que o governo não tenha a sociedade enquanto massa de manobra.

Reafirmando isso, podemos pensar hoje que a Educação tem por papel social fissurar e tensionar as outras instituições sociais na sociedade. E disto isso, é necessário salientar que, a Educação é um direito social fundamentado e apresentado pela Constituição da República Federativa do Brasil de 1988 - CF/1988, e está disposto no artigo $6^{\circ}$ dentre os demais direitos sociais.

Além dos artigos descritos na Carta Magna, a Educação brasileira é regida pela Lei no 9.394/1996 (LDB), que estabelece e as diretrizes e bases da educação nacional que foi alterada em 2003 no que diz respeito a inclusão de uma produção de 
conhecimento que enaltece os valores civilizatórios das populações africanas, afrobrasileiras e indígenas com objetivo de promover uma real igualdade de oportunidade de conhecimento sobre todas as nossas matrizes civilizatórias e originárias.

Foi por meio da Lei n ${ }^{0}$ 10.639/2003, que a Lei de Diretrizes e Bases da Educação (Lei $\mathrm{n}^{0}$ 9.394/1996) foi alterada incluindo e estabelecendo as diretrizes e bases da educação nacional, para incluir no currículo da Rede de Ensino a obrigatoriedade da temática "História e Cultura Afro-Brasileira", após 5 anos, a Lei no 11.645/2008 que Altera a Lei no 9.394, de 20 de dezembro de 1996, modificada pela Lei no 10.639, de 9 de janeiro de 2003, que estabelece as diretrizes e bases da educação nacional, para incluir no currículo oficial da rede de ensino a obrigatoriedade da temática "História e Cultura Africana, Afro-Brasileira e Indígena”.

Esse projeto se apoia nesses artifícios legais para que possa de fato compreender e tentar estancar a sangria do racismo que existe nas instituições sociais que está para uma população majoritariamente preta e parta, no caso do Brasil.

Essas leis, as Leis $\mathrm{n}^{0}$ 10.639/2003 e 11.645/2008, deve estar comboiada de políticas que gerem a discussão sobre os temas raciais, na escola, no bairro, no município, no país e no mundo. É preciso atentar que a lei vem para tentar estancar a sangria do racismo e esse não está presente apenas no espaço escolar, mas é vinculado em toda a sociedade. Se faz indispensável conhecer as Diretrizes Curriculares para a Educação das Relações Étnico-raciais e o Ensino de História e Cultura Afro-brasileira, Africana e Indígena.

Assim, a luz das Diretrizes Curriculares para a Educação das Relações Étnico-raciais e para o Ensino de História e Cultura Afro-brasileira e Africana, que trata dos conteúdos tradicionais das várias disciplinas, em especial o Art. $26^{\mathrm{a}}$ da Lei de Diretrizes e Bases da Educação nacional, (Lei 10.639/2003) - garantindo o que está preconizado desde a Constituição Federal em seu art. 3, IV, (...) 'o preconceito de origem de raça, sexo, cor, idade e quaisquer outras formas de discriminação' e reconhecem que todos são portadores de singularidade irredutível e que a formação escolar tem de estar atenta para o desenvolvimento de suas personalidades (Art. 208. IV) (ARRUDA, 2007, p. 9). 
Vemos que a não integração da população negra e indígena em múltiplos campos da sociedade ainda é invisível. Visto que, os negros compõem mais da metade da população brasileira, mas são minoria nos campos político, econômico, midiático, artístico, esportivo, educacional etc. As leis $n^{0}$ 10.639/2003 e 11.645/2008, desde sua promulgação não têm sido efetivamente aplicadas, uma vez que as leis supracitada não estão sendo cumprida, vendo assim, o acinte dos órgãos fiscalizadores e formadores, que mascaram um racismo institucionalizado, estrutural e institucional ou uma premissa para não cumprimento da Lei. A judicialização nestes casos torna-se um processo de vício do poder público cabendo a ele querer ou não, executar ou não as políticas e saberes referentes a História e cultura Afro-Brasileira, Africana e indígena.

\section{Um por todos e todos por um}

Por meio deste Relato de Experiência, apresentaremos um projeto de Pesquisa e Extensão Realizado pela Faculdade de Ensino Superior de Linhares-ES (Faceli) localizada no extremo norte capixaba.

A Faceli é uma Faculdade pública municipal que oferta o curso de Administração, Direito e Pedagogia, todos proporcionam prestações de serviço à comunidade, com destaque a Pedagogia que além de contribuir com a educação básica de Linhares-ES e região, também disponibiliza projetos e cursos gratuitos. Dentre eles está o projeto Black Power.

O projeto surge após o $1^{o}$ Fórum Linharense do Empoderamento Negro realizado em 24 de outubro de 2019. Devido o sucesso obtido no evento, alunos dos três cursos manifestaram interesse de participar de um projeto social para atender a comunidade sobre questões étnico - raciais. Por essa razão, planejou-se no fim de 2019, o Black Power, o mesmo foi aprovado pela instituição em dezembro de 2019. Neste ano de 2020.01 o projeto iniciou com atividades voltadas para os acadêmicos e para os munícipes de nossa cidade (FACELI, 2020a).

Além de atender às reivindicações dos universitários, a concretização do projeto Black Power se justifica pela necessidade de emponderar o negro para que assuma sua 
identidade com orgulho e lute por igualdade de direitos, de cultura e poder na sociedade. Destarte para acabar com a falsa democracia racial, visto que, pelo fato de não ter havido apartheid no Brasil, há uma lenda de que o racismo não existe. Infelizmente ele existe em todas as esferas da sociedade, inclusive nas escolas. Por essa razão, o curso de Pedagogia desenvolveu o projeto assumindo o desafio de promover ações étnico - raciais na cidade.

O brasileiro precisa reconhecer práticas de racismo dentro e fora da escola, e principalmente, aprender a neutralizar e inibir essas práticas através do diálogo, para quebrar esse ciclo vicioso arraigado em nossa sociedade por tantos séculos.

Mediante a relevância da temática, delineou-se o projeto para atender os acadêmicos e os cidadãos da cidade, e em especial as crianças, com principal objetivo de Desenvolver atitudes antirracistas na comunidade Linharense para minimizar os problemas causados pelo racismo nas diversas esferas da sociedade. Como objetivos específicos de: I- Promover estudo sobre etnocentrismo, racismo, antirracismo, democracia racial e demais assuntos importantes para o despertar do empoderamento negro; II- Realizar estudos de caso para combater o racismo na escola e demais setores da sociedade; III- Incentivar diálogos e discussões sobre o povo negro, sua cultural e empoderamento; IV - Concretizar ações dentro e fora da Faceli que mobilizem mais pessoas a militar sobre o empoderamento negro.

Incialmente como ações para o projeto planificou-se um curso presencial de 45 horas denominado de Cidadania e Consciência Negra, que por meio do edital 27/2020 (Faceli, 2020a) selecionou estudantes da Faceli e pessoas da comunidade que demonstraram interesse em ingressar nesta iniciativa.

Além do curso, o Black Power se propôs a oferecer o $2^{\circ}$ Fórum Linharense do Empoderamento Negro; Extensão às escolas através de visitas às instituições de ensino fundamental para promover palestras e debates Antirracistas; Curso de capoeira que selecionou pelo edital 20/2020 (Faceli, 2020b), crianças que tinham interesse de conhecer e aprender sobre a cultura negra; Realização de eventos acadêmicos para fomentar reflexões sobre o Racismo e a Cultura Negra.

Entretanto com a pandemia da COVID-19, houve a necessidade de adaptar o projeto. Decidiu-se pausar o curso de capoeira, retomando as atividades após a 
pandemia e não realizar as visitas às escolas devido à suspensão das aulas presenciais. Optou-se por dar prosseguimento às demais ações que haviam sido planejadas de forma remota pelo Google Classroom e lives por Instagran e YouTube.

\section{Do que foi plantado, há flores e frutos}

Segundo Gomes (2017), no Brasil, a escola, principalmente a pública, é resultado de uma luta popular pelo direito à educação e entendida como parte do processo de emancipação social. Outrora temos a escola como instituição social que está para regular e normatizar todas as ações do indivíduo, bem como estabelecer elos com a totalidade das relações sociais existentes no contexto social.

A partir do momento que a escola tem a função de estabelecer elos entre os sujeitos e a sociedade faz-se necessário o debate da instituição educacional enquanto a existência da multiplicidade racial existente no espaço educativo. $O$ acinte que se vê quando tratado dos estudos das histórias e culturas africanas e afro-brasileiras nestes espaços, se opõe à pedagogia da diversidade (de raça, de gênero, de idade, de culturas) que é apresentada por Gomes (2017), como potencial de derrubar os murros que separam o conhecimento e as experiências sociais.

O curso de Cidadania e Consciência Negra iniciou de forma presencial, na aula inaugural na sede da Faceli no dia 11 de março de 2020 com 30 cursista que participaram de uma palestra ministrada por um defensor público da União que atua na cidade de Linhares. Ele explanou sobre a lei de Cotas Raciais (Lei $\mathrm{n}^{0}$ 12.711/2012), a origem, a importância e sobre quais pessoas da sociedade devem requerer esse direito.

Como dito anteriormente, após a determinação de quarentena, o curso continuou na versão não presencial. Criou-se uma sala No Google Classroom para disponibilizar apostilas, slides, artigos, livros e vídeos do curso de Cidadania $e$ Consciência Negra. Através deste Ambiente Virtual de Aprendizagem (AVA), os cursistas obtiveram conhecimento sobre: Etnocentrismo, Tipos de racismo, cotas raciais, relativismo, falsa democracia racial, educação antirracista e reconhecimento de racismos na sociedade. 
Quinzenalmente era ofertado material para estudo e fóruns para interação dos cursistas (Freitas, 2020a, 2020b) de modo que expusessem sua opinião sobre o assunto e para que pudessem reconhecer as formas de racismo, sua origem, as causas e os efeitos deletérios que os mesmos provocam na sociedade brasileira.

Partindo da sugestão dos próprios cursistas, promoveu-se o segundo fórum Linharense do Empoderamento Negro com um professor $\mathrm{Dr}^{\circ}$ em Psicologia, por meio de live no Instagram. Com este evento conseguimos envolver mais de 60 pessoas, multiplicando saberes para além destes, pois a live está em um canal no Youtube onde pode ser visualizado por qualquer pessoa no mundo (FREITAS, 2020c).

Dessa forma on line, realizaram-se mesas redondas em formas de lives para dialogar sobre as temáticas propostas no Black Power. Assim, em Maio de 2020, ocorreu uma mesa redonda com um professor de História do IFES que palestrou sobre: O ser 'negro' em uma história branca. Evento que também teve participação da comunidade e ainda tem repercussão, pois está disponível no Youtube (FREITAS, 2020d).

No mês de julho realizou-se mais uma mesa redonda em forma de live, com o tema: Representatividade na política brasileira e o empoderamento negro, ministrada pelo mesmo Defensor Público da União que esteve presente na aula inaugural. Esse evento foi realizado no Youtube e teve a participação de diversas pessoas do país (FREITAS, 2020e).

Essa palestra de Julho encerrou o projeto no primeiro semestre, bem como o curso ofertado. Ao todo, 27 pessoas concluíram a formação e receberam certificado. Destes, 17 mostrou interesse de realizar ações antirracistas na cidade de Linhares-ES.

Após apresentação dos resultados e solicitação de continuidade do projeto, a Faceli optou por esperar acabar o período eleitoral para voltar com as atividades propostas pelo Black Power. Respaldando-se de modo que suas ações não sejam confundidas com propaganda eleitoral. Diante do exposto, o Black Power aguarda findar o período das eleições municipais, para ressurgir com todo esplendor que iniciou em fevereiro de 2020.

Entretanto, não se pode negar que dentre os objetos de luta promovidos pela população negra nos séculos XIX, XX e ao longo do século XXI, a educação constituiu- 
se em um relevante tema, tornando-se importante objeto de luta do Movimento Negro no século XX. Isso porque, os membros do mencionado Movimento admitem que o sistema educacional não é a solução para todos os problemas enfrentados pela população negra, mas consiste em importante instrumento para a formação dos pensamentos que os sujeitos constroem sobre si mesmos e sobre os outros sujeitos, além de viabilizar a constituição dos campos político e intelectual e, ser recorrentemente utilizado pelo mercado de trabalho como requisito para a escolha e exclusão dos indivíduos. (GOMES, 2011)

O racismo no Brasil é estrutural e estruturante nas relações sociais. Isso significa que a sociedade naturalizou toda a violência lançada contra os negros. A sociedade não se assusta com o fato de que a população carcerária brasileira seja composta majoritariamente por negros, nem com o fato de que o número de assassinatos atinja majoritariamente os jovens negros. Isso é tido como natural (ALMEIDA, 2016).

Dessa forma, pensar o racismo no Brasil não é pensar em atitudes praticadas por pessoas que são expressamente racistas, mas é pensar na própria estrutura social, na própria constituição dos campos e de suas regras de funcionamento. A luta contra o racismo, não é uma luta contra os racistas, mas uma luta pela transformação social (ALMEIDA, 2016).

\section{(IN)CONCLUSÕES}

Devido à pandemia da COVID-19 o projeto Black Power não conseguiu concretizar todos os seus objetivos, as aulas de capoeira que ocorreu apenas duas vezes, foram adiadas assim como as ações nas escolas da região. Todavia, as demais ações planejadas puderam ser adaptadas para o ambiente virtual de aprendizagem e ocorreram com muito sucesso.

O mesmo empecilho que dificultou o êxito em relação às crianças favoreceu a realização dos eventos acadêmicos on line que além de registrar na íntegra os momentos de reflexão para posterior estudo, também atingiu pessoas que residem em outros locais do Brasil, desta forma, os diálogos sobre as questões Étnico-Raciais saíram para além dos muros da Faceli e se eternizaram através do Youtube, onde 
atingirá um publico cada vez maior.

Embora a natureza estabeleça desafios para a espécie humana, prosseguindo com a seleção natural por meio de catástrofes e pandemias, precisamos mostrar a racionalidade de nossa espécie em criar técnicas de adaptação, de modo que os conhecimentos científicos e culturais continuem dissipando-se dentre na comunidade civil e científica.

Apenas pelo estudo e diálogo que se conseguirá perceber as manobras de poder e concentração de riquezas que implantaram o racismo outrora, e que infelizmente, se perpetua até os dias atuais. Ao se apropriar dos conhecimentos sobre a Origem, Causas e Manutenção Do Racismo na sociedade cada cidadão será capaz de reconhecê-lo e de desenvolver ações antirracistas no local onde vive.

Concluímos que para ter um país mais igualitário é imperioso ter mais projetos como o Black Power que possam envolver diversas pessoas da comunidade, inclusive as crianças. Se elas compreenderem que somos diferentes apenas nas características fenotípicas, e que tais diferenciações não originam espécies ou raças diferentes, e, portanto, todos merecem o mesmo tratamento, respeito e direitos, poderemos ter no futuro uma geração menos racista e com menos desigualdade social.

\section{Referências}

ALMEIDA, S.L. O que é racismo estrutural? TV BOITEMPO: Geledés - Instituto da Mulher Negra. O5 out. 2016. Disponível em: https://www.youtube.com/watch?v=PD4Ew5DIGrU\&feature=emb_logo Acesso em 10 jul 2019.

BRASIL, Presidência da República. Constituição da República dos Estados Unidos do Brasil (de 24 de Fevereiro de 1891).

BRASIL, Presidência da República. Lei no 10.639, de 9 de janeiro de 2003.

BRASIL, Presidência da República. Lei no 11.645, de 10 de março de 2008. EVARISTO, C. Tempo de nos aquilombar. Xapuri, 2020. Diponível em: < https://www.google.com.br/search?q=citar+pagina+da+internet+abnt $>$. Acesso em: 20 set. 2020.

FACELI. Edital 27/2020: Projeto Black Power. Linhares-ES, 2020. Disponível em:< https://faceli.edu.br/edital-027-2020-projeto-black-power-resultado/ >. Acesso em: 21, set. 2020a. 
FACELI. Edital 20/2020: Abertura de Vagas para o Curso de Capoeira. Linhares-ES, 2020. Disponível em: https://faceli.edu.br/edital-020-2020-abertura-de-vagas-parao-curso-de-capoeira/. Acesso em: 21, set. 2020b.

FREITAS, Joana Lúcia Alexandre de. Projeto Black Power: curso Cidadania e Consciência Negra- $1^{\text {a }}$ videoaula. Youtube, 2020. Disponível em:< https://www.youtube.com/watch?v=-KokOGh96Tw\&t=59s >. Acesso em: 21, set. 2020a.

FREITAS, Joana Lúcia Alexandre de. Projeto Black Power: curso Cidadania e Consciência Negra- $2^{\mathrm{a}}$ videoaula. Youtube, 2020. Disponível em:< https://www.youtube.com/watch?v=SC79i_jJseQ\&t=34S >. Acesso em: 21, set. 2020b.

FREITAS, Joana Lúcia Alexandre de. Projeto Black Power: Live do $2^{\circ}$ Fórum Linharense do Empoderamento Negro. Youtube, 2020. Disponível em:< https://www.youtube.com/watch?v=2yAAetsdqJI\&t=1783s >. Acesso em: 21, set. 2020c.

FREITAS, Joana Lúcia Alexandre de. Projeto Black Power: Mesa Redonda em Forma De Live: " O 'Ser' Negro em Uma História Branca".. Youtube, 2020. Disponível em:< https://www.youtube.com/watch?v=YUBpJBoCYKk\&t=2269s >. Acesso em: 21, set. 2020d.

FREITAS, Joana Lúcia Alexandre de. Projeto Black Power: Mesa Redonda em Forma De Live: "Representatividade na política brasileira e o empoderamento negro".. Youtube, 2020. Disponível em:< https://www.youtube.com/watch?v=MSxfMRH3WTM\&t=4307s >. Acesso em: 21, set. 2020e.

GOMES, N.L. O movimento negro educador. 1. ed. Petrópolis: Editora Vozes, 2017. v. 1. $154 \mathrm{p}$

MACEDO, Y. M. . Ser ou não ser? Desafios da diversidade na educação. In: $5^{\text {a }}$ Conferência Mundial Sobre Combate às Desigualdades Econômica Racial e Étnicas, 2018, Vitória. Anais da $5^{\mathrm{a}}$ Conferência Mundial Sobre Combate às Desigualdades Econômica Racial e Étnicas. Vitória: NEAB UFES, 2018. v. 1. p. 1.

\section{Sobre os autores:}

Joana Lúcia Alexandre de Freitas: Possui graduação em Ciências Biológicas pela Universidade de Cuiabá (2006), graduação em Química pela Universidade Metropolitana de Santos (2012) e mestrado em Ensino na Educação Básica pela 
Universidade Federal do Espírito Santo (2015). Atualmente é professora efetiva de Ciências da Prefeitura Municipal de Linhares e regente de classe efetiva no curso de pedagogia da Faculdade de Ensino Superior de Linhares- Faceli. Tem experiência na área de Biologia Geral, com ênfase em Genética e prática de ensino de ciências, atua principalmente nos seguintes temas: Ensino de Ciências Naturais, Empoderamento negro; Racismo e Antirracismo; Pedagogia, Histologia, Sexualidade e Orientação Sexual para alunos de séries iniciais; Educação Ambiental, Ensino de Artes. E-mail: joana.freitas@faceli.edu.br

Yuri Miguel Macedo: Professor Pesquisador do Núcleo de Estudos Afro-Brasileiros da Universidade Federal do Espirito Santo (UFES), Professor no Programa de PósGraduação Lato Sensu Formação de Professores em Letras-Libras na Universidade do Estado da Bahia (UNEB), Aluno do Programa de Po\&\#769;s-Graduação em Ensino e Relações E\&\#769;tnico-Raciais da Universidade Federal do Sul da Bahia, licenciado em Pedagogia pela Faculdade de Filosofia, Ciências e Letras de Boa Esperança FABIBE, Especialista em História e Cultura Afro-Brasileira, Especialista em Educação de Jovens e Adultos, atuando principalmente nos seguintes temas: Identidade, Cultura, Classe, Gênero, Educação Inclusiva, Educação, Devoções, Transversalidade, Africanidades e Ancestralidade. Coordenador do Grupo de Pesquisa Educação Transversal (UFES), vice coordenador do Grupo de Pesquisa Erê-Ecoa (UFES) Pesquisador dos grupos: Grupo de Pesquisas em Linguagens, Poder e Contemporaneidade - GELPOC (IFBA) ; Políticas de Inclusão e Educação para as Relações Étnico-Raciais (UFES); Espaços Deliberativos e Governança Pública (UFV/CLACSO) e Educação para as relações étnico-raciais, territorialidades e novas mídias (UFES). Membro da Associação Brasileira de Pesquisadores Negros (ABPN), Associação Nacional de Pós-Graduação e Pesquisa em Educação (ANPED), Société Internationale d'Ergologie (SIE) e Associação Brasileira de Ensino de Ciências Sociais (ABECS). E-mail: yurimacedo@id.uff.br 